\title{
Vitamin D status is associated with high BMI, working status and gravidity among pregnant Malaysian women
}

\author{
Lalitha Palaniveloo ${ }^{1}$, Yong Heng Yaw ${ }^{2}$, Zalilah Mohd Shariff ${ }^{*}$, Loh Su Peng ${ }^{2}$, \\ Jacques Bindels ${ }^{3}$, Yvonne Yee Siang Tee ${ }^{4}$ Eline M. van der Beek ${ }^{3,5}$
}

${ }^{1}$ Institute of Public Health, National Institutes of Health, Ministry of Health, Selangor, Malaysia; ${ }^{2}$ Department of Nutrition and Dietetics, Faculty of Medicine and Health Sciences, Universiti Putra Malaysia, Selangor, Malaysia; ${ }^{3}$ Danone Nutricia Research, Uppsalalaan, CT Utrecht, The Netherlands; ${ }^{4}$ Danone Dumex (M) Shd Bhd, Nilai, Negeri Sembilan, Malaysia; ${ }^{\mathbf{5}}$ Department of Pediatrics, University Medical Centre Groningen, University of Groningen, Groningen, The Netherlands

\begin{abstract}
Introduction: Vitamin D deficiency (VDD) is associated with adverse health outcomes in pregnancy and newborns. This study aims to determine the Vitamin D status among pregnant Malaysian women and its associations with specific maternal \& pregnancy characteristics. Methods: This study utilised cross-sectional data from a prospective cohort study of pregnant women in Seremban district in which 259 pregnant women had available vitamin D data. Blood samples were taken $<14^{\text {th }}$ week of gestation. Serum 25-hydroxy Vitamin D [25(OH)D] levels were analysed using chemiluminescent microparticle immunoassay (CMIA) technology on the ARCHITECT iSystem and categorised using the Institute of Medicine (IOM) 2011 cutoffs. A set of pre-tested interviewer-administered questionnaire was used to obtain information on socio-demographics, obstetrics, and anthropometry. Results: Mean serum 25(OH)D was $32.83 \pm 11.37 \mathrm{nmol} / \mathrm{L}$. The prevalence of severe and mild VDD was $23.2 \%(n=60)$ and $68.3 \%$ $(n=177)$, respectively. About $8.5 \%(n=22)$ of pregnant women were vitamin $\mathrm{D}$ insufficient and none had sufficient serum $25(\mathrm{OH}) \mathrm{D}(>75 \mathrm{nmol} / \mathrm{L})$. Early pregnancy body mass index $(A O R=2.95$, $95 \% \mathrm{CI}=1.03-8.47)$, working status $(A O R=3.17,95 \% \mathrm{CI}=1.06-9.50)$ and gravidity $(A O R=0.68$, 95\% CI=0.48-0.98) were significantly associated with VDD. Conclusion: The present study showed a high prevalence of VDD among pregnant women in Malaysia, especially among those who were overweight or obese, working in indoor environment and primigravida.
\end{abstract}

Keywords: Vitamin D deficiency (VDD), serum 25(OH)D, BMI, pregnant women, Malaysia

\section{INTRODUCTION}

Vitamin D deficiency (VDD) (serum 25-hydroxy Vitamin D [25(OH)D] $<50 \mathrm{nmol} / \mathrm{L}$ ) has become a public health concern globally, cutting across all age groups. In Europe, about 30-65\% of adults were reported having VDD, while in Asia, the prevalence among adults was about 50-70\% (Palacios \& Gonzalez, 2014). Among healthy women in the reproductive age of between 15-45 years old, the prevalence of VDD was 60-73\% in Asia (Green et al., 2008; Junaid et al., 2015), while in the United States it was 41\% (Ginde et al., 2010). To date, consensus regarding

\footnotetext{
*Corresponding author: Zalilah Mohd Shariff

Department of Nutrition and Dietetics, Faculty of Medicine and Health Sciences

Universiti Putra Malaysia, Selangor, Malaysia

Tel: (6)03 97692472; Fax: (6)(03) 89426769; E-mail: zalilahms@upm.edu.my

doi: https://doi.org/10.31246/mjn-2020-0010
} 
optimal levels of serum 25(OH)D has not been established, although most experts define VDD as serum 25(OH) $\mathrm{D}$ level of $<20 \mathrm{ng} / \mathrm{ml}(50 \mathrm{nmol} / \mathrm{L})$ and vitamin D insufficiency as $21-29 \mathrm{ng} / \mathrm{ml}$ (52-72nmol/L) (IOM, 2011).

The traditional function of vitamin $\mathrm{D}$ is associated with musculoskeletal health and bone mineralisation. However, there are increasing evidences supporting the association between VDD with cardiovascular diseases, cancer, autoimmune diseases and diabetes (Kulie et al., 2009). The beneficial effects of vitamin $\mathrm{D}$ in reducing the risk of cardiovascular diseases appear to be via its role in the regulation of blood pressure, weakening the actions of the renin-angiotensin-aldosterone system and suppressing cellular inflammation of cardiac cells (Wimalawansa, 2016). Vitamin D also acts as an antiinflammatory agent and assists in maintaining the equilibrium between pro- and anti-inflammatory situations in autoimmune diseases (Dankers et al., 2017). In addition, vitamin $\mathrm{D}$ and its metabolites reduce the incidence of cancer by inhibiting cell proliferation, stimulating apoptosis, suppressing inflammation, as well as inhibiting tumour angiogenesis, invasion and metastasis (Krishnan et al., 2012). Meanwhile, the role of vitamin D in glucose tolerance is demonstrated by its ability to affect insulin secretion from $\beta$-cells in the pancreas and insulin sensitivity (Martin \& Campbell, 2011).

VDD is also common during pregnancy with a prevalence in the range of $21-91 \%$ across developed and developing countries (Ravinder et al., 2015; Richard, Rohrmann \& Lötscher, 2017). VDD in pregnancy has been associated with adverse pregnancy outcomes, including gestational diabetes mellitus (GDM), preeclampsia, bacterial vaginosis, a shorter gestation period, increase in caesarean section births and post-partum depression (Charatcharoenwitthaya et al., 2013). Adverse associations of VDD on newborns include higher incidences of small-for-gestational age (SGA), reduced infant bone mineral density and rickets (Mulligan et al., 2010). Infants born to women with VDD are also at risk for developing respiratory infections, asthma, type 1 diabetes and schizophrenia later in life (Mulligan et al., 2010; Hart et al., 2015). Among the established risk factors for VDD in pregnancy are high latitude, winter season and high body mass index (BMI) (Vandevijvere et al., 2012). Meanwhile, physical activity level, ethnicity, educational level and exposure to sunlight showed inconsistent associations with vitamin D status (Wagner et al., 2016; Bukhary et al., 2016). Dietary intake and exposure to sunlight are the two main sources of Vitamin D. However, due to limited food sources of Vitamin D, either naturally present in foods or added to foods, exposure to sunlight is therefore regarded as the main source of Vitamin D in most countries (Holick, 2017).

In Malaysia, despite the abundance of sunlight, nearly $70 \%$ of adults have been reported to be vitamin $\mathrm{D}$ deficient (Shafinaz \& Moy, 2016). However, data on VDD incidence among pregnant women in the country are limited. Bukhary et al. (2016) reported that about $90.4 \%$ of pregnant mothers in Selangor had VDD and that the median of Vitamin D level was $27.11 \mathrm{nmol} / \mathrm{L}$. Jan Mohamed et al. (2014) reported that about twothirds $(59.8 \%)$ of pregnant mothers in their second trimester of pregnancy in Kelantan showed VDD. Thus, this study aimed to further investigate the prevalence of VDD among Malaysian pregnant women, as well as factors associated with vitamin D status. 


\section{MATERIALS AND METHODS}

This study utilised cross-sectional data from The Seremban Cohort Study (SECOST), which was a prospective cohort study where pregnant women and their infants were followed-up until two years postnatal. Women in their first trimester of pregnancy $\left(<14^{\text {th }}\right.$ week of gestation) were recruited from three Maternal and Child Health ( $\mathrm{MCH})$ clinics in the district of Seremban, Negeri Sembilan. The details of this study have been previously reported (Yong et al., 2018). A total of 259 pregnant women whose vitamin D data were collected were included in this study. The sample size was determined by exclusion of individuals diagnosed with diabetes in pregnancy (DIP) or GDM by the $\mathrm{MCH}$ clinics $(n=57)$, miscarriage $(n=28)$, and drop-out or loss of contact during study period $(n=44)$, participants who withdrew $(n=38)$, and those without available vitamin $\mathrm{D}$ data $(n=311)$ (Figure 1$)$.

A set of pre-tested intervieweradministered questionnaires was used for data collection. Demographic and socioeconomic information obtained were age, ethnicity, marital status, educational level, monthly household income, household size, as well as gravidity. Respondents' weight and height were measured at study enrolment using standard instruments (SECA digital weighing scale, and SECA body meter). Early pregnancy body weight was obtained from the medical records at the health clinics. Early pregnancy height and body weight were used to calculate early pregnancy BMI, as weight $(\mathrm{kg})$ divided by the square of height $\left(\mathrm{m}^{2}\right)$. Fasting venous blood samples $(5 \mathrm{ml})$ were drawn into a plain tube during the booking period $1<14^{\text {th }}$ week of gestation) by trained nurses to quantify serum 25(OH)D. Maternal serum 25(OH)D levels were analysed using chemiluminescent microparticle immunoassay (CMIA) technology on the ARCHITECT iSystem and categorised as severe VDD $(<25 \mathrm{nmol} / \mathrm{L})$, mild VDD $(25-<50 \mathrm{nmol} / \mathrm{L})$, vitamin D insufficiency $(50-<75 \mathrm{nmol} / \mathrm{L})$ and vitamin D sufficiency ( $\geq 75 \mathrm{nmol} / \mathrm{L}$ ) (IOM, 2011).

The study protocol was approved by the Medical Research Ethics Committee

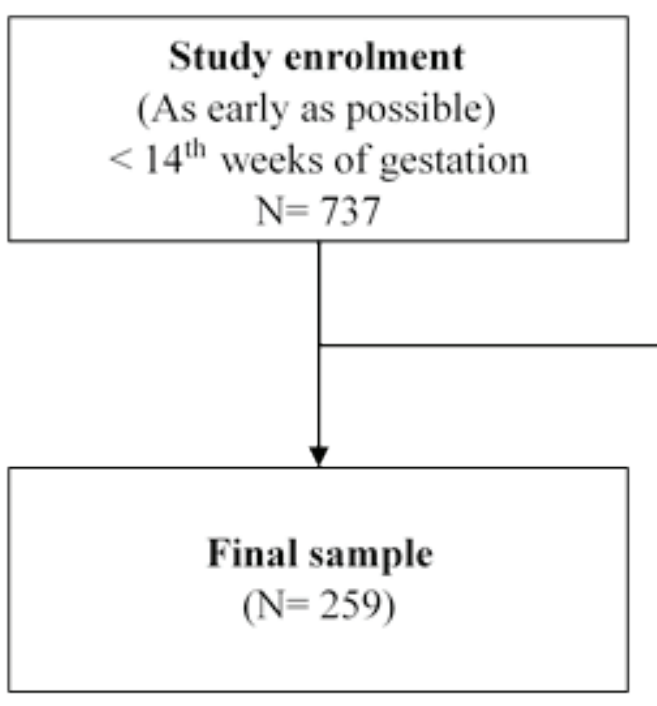

\section{Excluded 478}

- 57 diagnosed with diabetes in pregnancy

- 28 miscarriages

- 44 lost contact/transferred to other clinics

- 38 withdrew

- 311 without vitamin D data

Figure 1. Sampling procedure 
(MREC), Universiti Putra Malaysia (UPM/FPSK/100-9/2-MJKEtika) and the Medical Research Ethics Committee (MREC), Ministry of Health Malaysia (KKM / NIHSEC/08/0804/P12-613). Permission to conduct this study was also obtained from the Head of the Seremban District Health Office. All women gave informed consent prior to study enrolment.

\section{Statistical analysis}

Statistical analysis was performed using the SPSS statistical software package version 22 (SPSS Inc., Chicago, IL, USA). Exploratory Data Analysis (EDA) was carried out to determine the normality and homogeneity of the data. All variables were described using descriptive statistics. Chi-square test of independence or the Fisher's exact test and Analysis of Variance (ANOVA) test were used to assess the associations between the characteristics of women with serum Vitamin D levels, for categorical and continuous variables, respectively.

Multiple logistic regression was performed to determine the associations between the independent variables and VDD, and adjusted for covariates. Covariates included in the multivariable model were age, ethnicity and years of education. Adjusted odds ratio (OR) with $95 \%$ confidence interval (CI) were presented. Statistical significance was set at $p<0.05$.

\section{RESULTS}

The distributions of serum $25(\mathrm{OH})$ $\mathrm{D}$ are shown in Figure 2. Mean serum $25(\mathrm{OH}) \mathrm{D}$ was $32.83 \pm 11.37 \mathrm{mmol} / \mathrm{L}$. The prevalence of severe and mild serum 25(OH)D deficiency was $23.2 \% \quad(n=60)$ and $68.3 \%(n=177)$, respectively. About $8.5 \%$ of the pregnant women $(n=22)$ were found to have serum 25(OH)D insufficiency. None of the women showed sufficient serum 25(OH)D $(>75 \mathrm{nmol} / \mathrm{L})$ levels according to the Institute of Medicine (IOM) criteria.

Table 1 describes the sociodemographic and obstetrical characteristics of pregnant women in the study. The mean age of women in the study cohort was $30.50 \pm 4.42$ years, majority being Malay (93.4\%) and employed $(73.0 \%)$. The mean years of

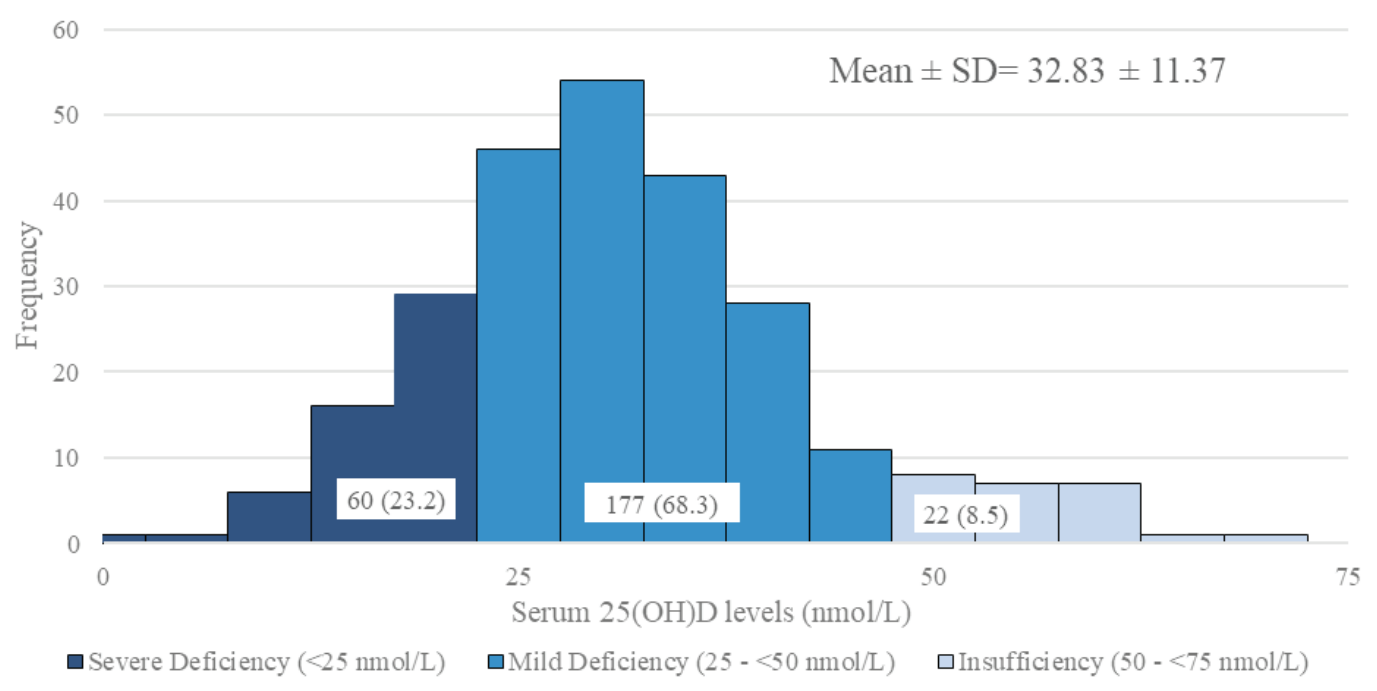

Figure 2. Distribution of serum 25(OH)D levels in pregnant women $(N=259)$ 
Vitamin D status among Malaysian pregnant women

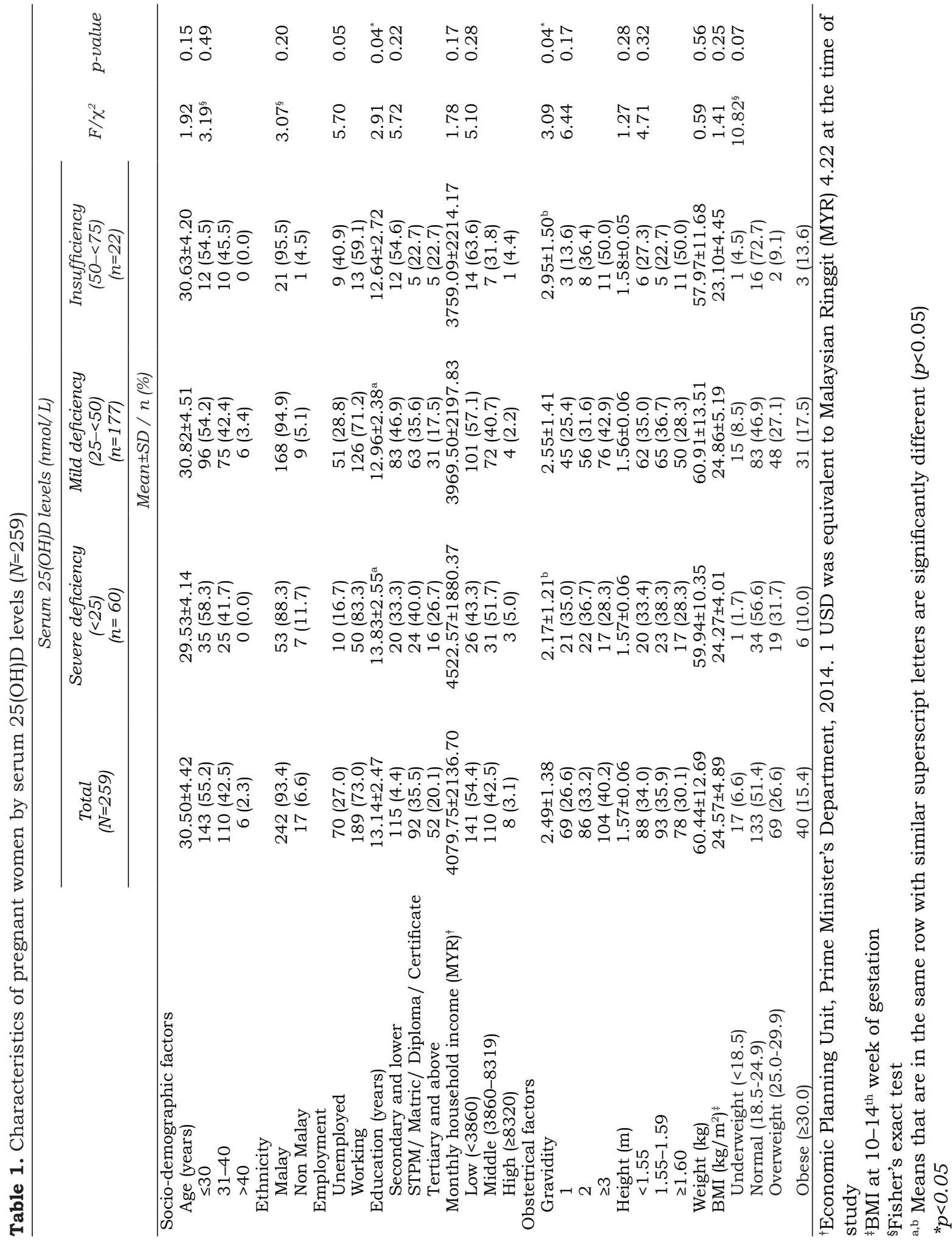


Table 2. Unadjusted OR and $95 \%$ CI of factors associated with serum 25(OH)D levels in pregnant women $(N=259)$

\begin{tabular}{|c|c|c|c|c|}
\hline & \multicolumn{4}{|c|}{ Serum 25(OH)D levels $(\mathrm{nmol} / \mathrm{L})$} \\
\hline & \multicolumn{2}{|c|}{$\begin{array}{l}\text { Severe deficiency } \\
\quad(<25)(n=60)\end{array}$} & \multicolumn{2}{|c|}{$\begin{array}{l}\text { Mild deficiency } \\
(25-<50)(n=177)\end{array}$} \\
\hline & $\begin{array}{c}\text { Unadjusted OR } \\
\text { [95\% CI] }\end{array}$ & $p$-value & $\begin{array}{c}\text { Unadjusted OR } \\
\text { [95\% CI] }\end{array}$ & p-value \\
\hline \multicolumn{5}{|l|}{ Socio-demographic factors } \\
\hline Age (years) & $0.94[0.84-1.05]$ & 0.29 & $1.01[0.91-1.12]$ & 0.85 \\
\hline \multicolumn{5}{|l|}{ Ethnicity } \\
\hline Malay & 1.00 & & 1.00 & \\
\hline Non Malay & $2.77[0.32-23.94]$ & 0.35 & $1.13[0.14-9.33]$ & 0.91 \\
\hline \multicolumn{5}{|l|}{ Employment } \\
\hline Unemployed & 1.00 & & 1.00 & \\
\hline Working & $3.46[1.17-10.27]$ & $0.03^{*}$ & $1.71[0.69-4.25]$ & 0.25 \\
\hline \multicolumn{5}{|l|}{ Education (years) } \\
\hline Secondary and lower & 1.00 & & 1.00 & \\
\hline $\begin{array}{l}\text { STPM/ Matric/ Diploma/ } \\
\text { Certificate }\end{array}$ & $2.88[0.87-9.56]$ & 0.08 & $1.82[0.61-5.44]$ & 0.28 \\
\hline Tertiary and above & $1.92[0.56-6.59]$ & 0.30 & $0.90[0.29-2.75]$ & 0.85 \\
\hline \multicolumn{5}{|l|}{ Monthly household income (MYR) ${ }^{\dagger}$} \\
\hline Low $(<3860)$ & 1.00 & & 1.00 & \\
\hline Middle (3860 - 8319) & $2.39[0.84-6.79]$ & 0.10 & $1.43[0.55-3.71]$ & 0.47 \\
\hline High $(\geq 8320)$ & $1.62[0.15-17.02]$ & 0.69 & $0.55[0.06-5.32]$ & 0.61 \\
\hline \multicolumn{5}{|l|}{ Obstetrical factors } \\
\hline \multicolumn{5}{|l|}{ Gravidity } \\
\hline 1 & 1.00 & & 1.00 & \\
\hline 2 & $0.39[0.09-1.68]$ & 0.21 & $0.47[0.12-1.86]$ & 0.28 \\
\hline$\geq 3$ & $0.22[0.05-0.92]$ & $0.04^{*}$ & $0.46[0.12-1.74]$ & 0.25 \\
\hline \multicolumn{5}{|l|}{ Height (m) } \\
\hline$<1.55$ & 1.00 & & 1.00 & \\
\hline $1.55-1.59$ & $0.83[0.37-5.22]$ & 0.64 & $0.94[0.36-4.33]$ & 0.72 \\
\hline$\geq 1.60$ & $0.46[0.14-1.52]$ & 0.20 & $0.44[0.15-1.27]$ & 0.13 \\
\hline \multicolumn{5}{|l|}{ BMI $\left(\mathrm{kg} / \mathrm{m}^{2}\right)^{\ddagger}$} \\
\hline Non-overweight/obese $(<25.0)$ & 1.00 & & 1.00 & \\
\hline Overweight/obese $(\geq 25.0)$ & $2.43[0.79-7.45]$ & 0.12 & $2.74[0.97-7.76]$ & $0.04^{*}$ \\
\hline \multicolumn{5}{|c|}{ 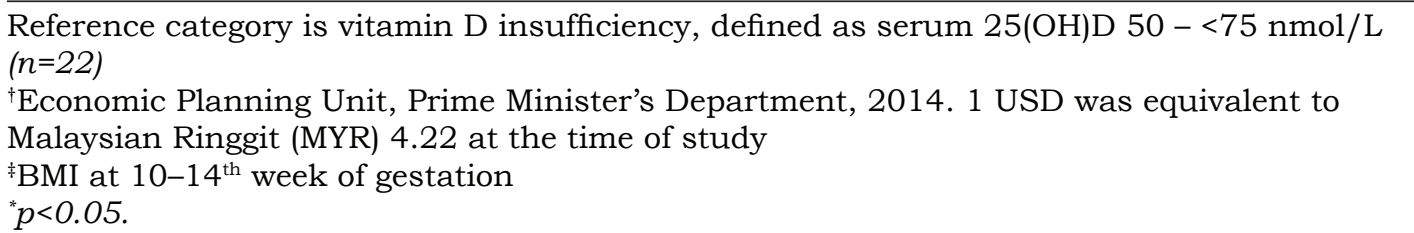 } \\
\hline
\end{tabular}

education was $13.14 \pm 2.47$ years, and the mean monthly household income was RM4,079.57 $\pm 2,136.70$. Mean gravidity was $2.49 \pm 1.38$. Mean height and weight of the pregnant women were $1.57 \pm 0.06 \mathrm{~m}$ and $60.44 \pm 12.69 \mathrm{~kg}$, respectively. The calculated early pregnancy mean BMI amounted to $24.57 \pm 4.89 \mathrm{~kg} / \mathrm{m}^{2}$, indicating that approximately half of the women (51.4\%) had a healthy BMI.
Among the variables, only years of education and gravidity were significantly associated with serum 25(OH)D levels.

Table 2 and Table 3 describe the unadjusted and adjusted $O R$ and 95\% CI for factors associated with serum $25(\mathrm{OH}) \mathrm{D}$ levels in pregnant women. In the unadjusted logistic model, early pregnancy $\mathrm{BMI}(\mathrm{OR}=2.74,95 \% \mathrm{CI}=0.97$ 7.76), employment status (OR=3.46, 95\% 
Vitamin D status among Malaysian pregnant women

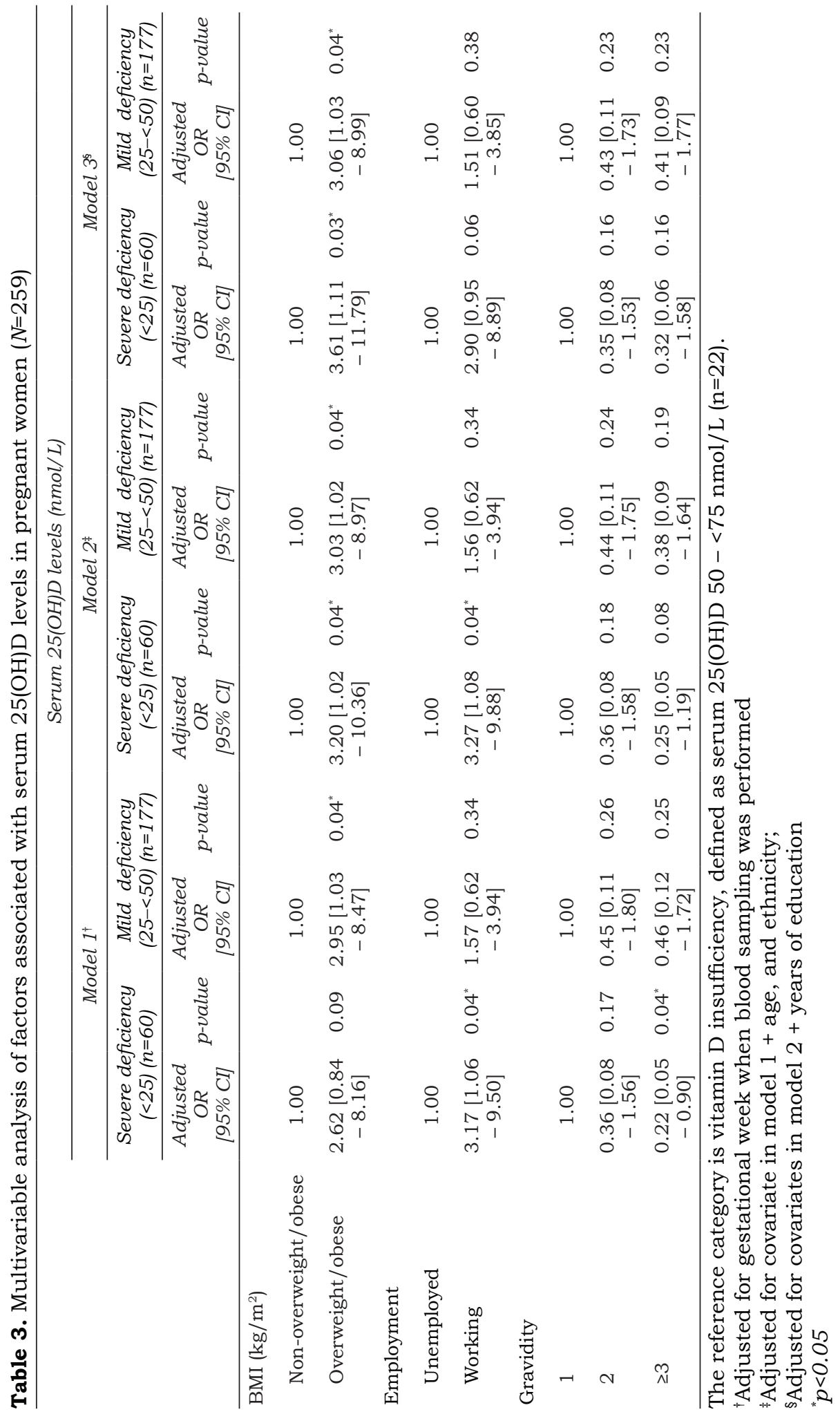


$\mathrm{CI}=1.17-10.27)$ and gravidity $(O R=0.22$, 95\% CI=0.05-0.92) were significantly associated with vitamin D status (Table 2). Overweight/obese pregnant women were three times at higher risks for severe $(A O R=3.61,95 \% \mathrm{CI}=1.11-11.79)$ and mild $(A O R=3.06,95 \% \mathrm{CI}=1.03-8.99)$ VDD compared to non-overweight/ obese pregnant women. The significant association between early pregnancy BMI and VDD persisted after adjusting for covariates. Working pregnant women were 3.27 times more likely to have severe serum 25(OH)D deficiency compared to unemployed pregnant women $(A O R=3.27,95 \% \mathrm{CI}=1.08-9.88)$. However, this association was no longer significant after further adjustment for years of education. Pregnant women with gravidity $\geq 3$ were less likely to have severe VDD compared to primigravid women $(A O R=0.22,95 \% \mathrm{CI}=0.05-0.90)$. Yet again, significance was lost when the models were adjusted for age, ethnicity and years of education.

\section{DISCUSSION}

The present study showed that about $91.5 \%$ of pregnant women in their early pregnancy had severe to mild VDD (serum $25(\mathrm{OH}) \mathrm{D}<50 \mathrm{nmol} / \mathrm{L})$. These results appear to be quite similar to the results in a local study conducted in Selangor which reported that about $90.4 \%$ of pregnant women in their first trimester of pregnancy had VDD (Bukhary et al., 2016). Although lower prevalence of VDD has been reported among women in the first trimester of pregnancy in Thailand (26.7\%) and Vietnam (19.0\%) (Charatcharoenwitthaya et al., 2013; Hien et al., 2011), direct comparison between studies should be done with caution, as the method to analyze serum vitamin D (Charatcharoenwitthaya et al., 2013) and cut-offs to define VDD (Hien et al. 2011) were different. Lack of exposure to sunlight cannot explain these observed differences in VDD prevalence as Malaysia, Thailand and Vietnam are all tropical countries with abundant sunlight throughout the year. A plausible explanation could be the differences in dressing attire of women. Since approximately $93.4 \%$ of pregnant women in the present study were Muslims, thus they are covered in dressing attires that exposed less skin surface to sunlight. Previous studies have shown that covered dressing style due to religious or cultural factors, is indeed an important determinant of VDD in Muslim populations (Parlak et al., 2012).

Low mean serum 25(OH)D and high prevalence of VDD were also reported for non-pregnant women in Malaysia. Green et al. (2008) found that women of child-bearing age living in Kuala Lumpur had a low mean serum $25(\mathrm{OH})$ $\mathrm{D}$ of $49.0 \mathrm{nmol} / \mathrm{L}$ and the percentage of women with severe $(<17.5 \mathrm{nmol} / \mathrm{L})$ and mild $(<50 \mathrm{nmol} / \mathrm{L})$ VDD were $0.3 \%$ and $60.0 \%$, respectively. Studies among workers in a public university (Moy \& Bulgiba, 2011) and secondary school teachers (Shafinaz \& Moy, 2016) reported an overall VDD prevalence of 67.4 and $67.9 \%$, respectively. These two studies also showed that women (36.2-43.5nmol/L) had significantly lower mean serum 25(OH)D than men (56.2-63.1 nmol/L).

In the present study, early pregnancy BMI was significantly associated with vitamin D status. Previous studies also indicated that overweight or obese pregnant women were more likely to have VDD compared to normal weight pregnant women (Vandevijvere et al., 2012; Karlsson et al., 2015). Variability in vitamin $\mathrm{D}$ status by adiposity can be explained by the role of subcutaneous fat, which is the storage site for cutaneous synthesised Vitamin D3. In an obese person, vitamin D3 will be actively retained in the subcutaneous 
fat, which then reduces the conversion of vitamin D3 to $25(\mathrm{OH}) \mathrm{D}$ in the liver, causing low circulating levels of serum 25(OH)D (Wortsman et al., 2000). Another possible explanation for the association of Vitamin D and adiposity is through volumetric dilution mechanism. Vitamin D is fat soluble and stored mainly in fat, muscles, and liver, with smaller amounts in other tissues. As all these tissues and organs expand in an obese person, there will be increased amount of vitamin D distributed into these tissues and organs, consequently decreasing the amount of vitamin $D$ in the circulation (Walsh, Bowles \& Evans, 2017).

The study found that employed pregnant women were more likely to have severe VDD compared to unemployed pregnant women. This could be due to the nature of jobs that require women to work in a closed environment with limited sun exposure. In China, pregnant women who were working indoors with limited exposure to sunlight were reported to have an average level of $36.7 \mathrm{nmol} / \mathrm{L}$ of serum 25(OH)D (Xiang et al., 2013). Studies have reported that limited exposure to sunlight affects Vitamin D level in the body as the synthesis of vitamin D in human body depends predominantly on skin exposure to Ultraviolet (UV) B light from direct sunlight (Flood-Nichols et al., 2015). Furthermore, usage of sunblock lotions could also limit the ability of the skin to synthesise Vitamin D (Wagner et al., 2016). Interestingly, the present study showed that gravidity was significantly associated with VDD where pregnant women with gravidity $\geq 3$ were less likely to have severe VDD compared to primigravid women. Further analyses were performed to assess the associations between gravidity with employment status and BMI. While BMI did not show any significant association with gravidity, there were significantly more primigravid women who were employed (76.8\%) compared to women with gravidity $\geq 3(23.2 \%)$. This observation supports our finding that employed women were at higher risks of VDD due to working environment that limits exposure to sunlight.

The inability to evaluate the underlying factors contributing to VDD such as usage of sunscreen lotion, skin pigmentation, socio-economic status and lifestyle behaviours was a limitation of this study. Applying early pregnancy BMI as a contributing factor instead of pre-pregnancy BMI where the latter has been widely used to ascertain the association between maternal VDD and BMI was also noted as a limitation in this study. Nevertheless, the use of early pregnancy BMI could help to avoid recall bias by pregnant women in reporting their pre-pregnancy BMI. Vitamin D intake (from foods and dietary supplements) and sun exposure are major determinants of vitamin D status. Sun exposure was not measured in the study although the working status of women in the study could be a proxy to the amount of sun exposure. For vitamin $\mathrm{D}$ intake, an analysis of sub-sample $(N=170)$ showed that mean vitamin D intake from foods and supplements were $4.65 \pm 0.34 \mu \mathrm{g} /$ day and $2.58 \pm 0.42 \mu \mathrm{g} /$ day (data not shown), respectively. However, no significant association between total vitamin D intake and serum 25(OH) $\mathrm{D}$ was observed in this sub-sample of women. Despite these limitations, this study adds to the existing limited findings on serum 25(OH)D levels in the first trimester of pregnancy.

\section{CONCLUSION}

VDD is prevalent in this selected sample of pregnant women and among those who were overweight or obese, working and had lower gravidity. It is important to promote awareness on the importance of 
Vitamin D during pregnancy as vitamin $\mathrm{D}$ is essential not only for healthy bones, but also plays a role in disease prevention and health outcomes for both the mother and her offspring. Educating pregnant women on maintaining a healthy BMI and gaining adequate weight throughout pregnancy should be conducted to minimise the risk of VDD among them. Health care system should consider providing VDD screening to pregnant women during early pregnancy for consideration of advice or intervention. Pregnant women should be encouraged to consume vitamin D-rich foods, but even more importantly, to be exposed to adequate sunlight regularly to increase endogenously synthesised Vitamin D.

\section{Acknowledgements}

We would like to thank Danone Dumex (Malaysia) Sdn.Bhd. for the funding and financial support and the study participants for their time and cooperation. We also would like to thank the Director General of Health Malaysia for his permission to publish this article.

\section{Authors' contributions}

LP, analysed the data and constructed the draft manuscript, contributed to the review and approval of the final manuscript; YHY, responsible for the concept and project development, supervised the project's progress; contributed to the review and approval of the final manuscript; ZMS, responsible for the concept and project development, supervised the project's progress, contributed to the review and approval of the final manuscript; LSP, responsible for the concept and project development, supervised the project's progress, contributed to the review and approval of the final manuscript; JB, responsible for the concept and project development, contributed to the review and approval of the final manuscript; YYST, responsible for the concept and project development, contributed to the review and approval of the final manuscript; EMVDB, responsible for the concept and project development, contributed to the review and approval of the final manuscript.

\section{Conflict of interest}

The authors declare that they have no conflict of interests. The funders had no roles in data collection, data analysis or data interpretation.

\section{References}

Bukhary N, Md Isa Z, Shamsuddin K, GL Khor, Mahdy ZA, Hassan H \& Yeop NSH (2016). Risk factors for antenatal hypovitaminosis D in an urban district in Malaysia. BMC Pregnancy Childbirth 16:156.

Charatcharoenwitthaya N, Nanthakomon T, Somprasit C, Chanthasenanont A, Chailurkit L, Pattaraarchachai J \& Ongphiphadhanakul B (2013). Maternal vitamin D status, its associated factors and the course of pregnancy in Thai women. Clin Endocrinol 78:126-133.

Dankers W, Colin EM, van Hamburg JP \& Lubberts E (2017). Vitamin D in autoimmunity: molecular mechanisms and therapeutic potential. Front Immunol 7:697.

Flood-Nichols SK, Tinnemore D, Huang RR, Napolitano PG \& Ippolito DL (2015). Vitamin $\mathrm{D}$ deficiency in early pregnancy. PLoS ONE 10:e0123763.

Ginde AA, Sullivan AF, Mansbach JM \& Camargo CA Jr (2010). Vitamin D insufficiency in pregnant and nonpregnant women of childbearing age in the United States. Am.J Obstet.Gynecol 202(5):436.e1-436.e8.

Green TJ, Skeaff CM, Rockell JEP, Venn BJ, Lambert A, Todd J, Khor GL, Loh SP, Muslimatun S, Agustina R \& Whiting SJ (2008). Vitamin D status and its association with parathyroid hormone concentrations in women of child-bearing age living in Jakarta and Kuala Lumpur. Eur J Clin Nutr 62:373-378.

Hart PH, Lucas RM, Walsh JP, Zosky G, Whitehouse A, Zhu K, Allen KL, Kusel MM, Anderson D \& Mountain JA (2015). Vitamin $\mathrm{D}$ in fetal development: findings from a birth cohort study. Pediatrics 135:1.e168.

Hien V, Lam N, Skeaff C, Todd J, Mclean J \& Green $T$ (2011). Vitamin D status of pregnant and non-pregnant women of reproductive age living in Hanoi City and the Hai Duong province of Vietnam. Matern Child Nutr 8(4):533-539.

Holick MF (2017). Ultraviolet B radiation: the vitamin D connection. Adv Exp Med Biol 996:137-154.

IOM (2011). Dietary Reference Intakes for calcium and Vitamin D. Institute of Medicine. The National Academy Press, Washington, DC.

Jan Mohamed HJ, Rowan A, Fong B \& Loy SL (2014). Maternal serum and breast milk vitamin D Levels: findings from the Universiti Sains Malaysia pregnancy cohort study. PLoS ONE 9(7):e100705. 
Junaid K, Rehman A, David A, Wood K \& Martineau A (2015). High prevalence of vitamin $\mathrm{D}$ deficiency among women of child-bearing age in Lahore Pakistan, associating with lack of sun exposure and illiteracy. BMC Womens Health 15:83.

Karlsson T, Andersson L, Hussain A, Bosaeus M, Jansson N, Osmancevic A, Hulthen L, Holmang A \& Larsson I (2015). Lower vitamin D status in obese compared with normal-weight women despite higher vitamin $D$ intake in early pregnancy. Clin Nutr 34(5):892-8.

Krishnan AV, Trump DL, Johnson CS \& Feldman D (2012). The role of vitamin D in cancer prevention and treatment. Rheum Dis Clin North Am 38(1):161-178.

Kulie T, Groff A, Redmer J, Hounshell J \& Schrager S (2009). Vitamin D: an evidence-based review. $J$ Am Board Fam Med 22:698-706.

Martin T \& Campbell KR (2011). Vitamin D and diabetes. Diabetes Spectr 24:2.

Moy FM \& Bulgiba A (2011). High prevalence of vitamin $\mathrm{D}$ insufficiency and its association with obesity and metabolic syndrome among Malay adults in Kuala Lumpur, Malaysia. BMC Public Health 11(1):735.

Mulligan ML, Felton SK, Riek AE \& BernalMizrachi C (2010). Implications of vitamin D deficiency in pregnancy and lactation. Am J Obstet Gynecol 202:429.e1-9.

Palacios C \& Gonzalez L (2014). Is vitamin D deficiency a major global public health problem? $J$ Steroid Biochem Mol Biol 144PA:138-145.

Parlak M, Kalay S, Kalay Z, Kirecci A, Guney O $\&$ Koklu E (2012). Severe vitamin D deficiency among pregnant women and their newborns in Turkey. J Matern Fetal Neonatal Med 28(5):54851.

Ravinder S, Deepika C, Padmavathi R, Balakrishnan K \& Vijayaraghavan J (2015). Occurrence of vitamin D deficiency in pregnant women in South India-a preliminary study. Int J Pure App Biosci 3(2):291-296.
Richard A, Rohrmann S \& Quack Lötscher KC (2017). Prevalence of vitamin D deficiency and its associations with skin colour in pregnant women in the first trimester in a sample from Switzerland. Nutrients 9:260.

Shafinaz IS \& Moy FM (2016). Vitamin D level and its association with adiposity among multiethnic adults in Kuala Lumpur, Malaysia: a cross sectional study. BMC Public Health $16: 232$.

Vandevijvere S, Amsalkhir S, Van Oyen H \& Moreno-Reyes R (2012). High prevalence of vitamin $\mathrm{D}$ deficiency in pregnant women: a national cross-sectional survey. PLOS ONE $7(8): e 43868$.

Wagner CL, Baggerly C, McDonnell S, Baggerly KA, French CB, Baggerly L, Hamiltond SA \& Hollis BW (2016). Post-hoc analysis of vitamin D status and reduced risk of preterm birth in two vitamin D pregnancy cohorts compared with South Carolina March of Dimes 2009-2011 rates. J Steroid Biochem Mol Biol 155:245-251.

Walsh JS, Bowles S \& Evans AL (2017). Vitamin D in obesity. Curr Opin Endocrinol Diabetes Obes 24(6):389-394.

Wimalawansa SJ (2016). Vitamin D adequacy and improvements of comorbidities in persons with intellectual developmental disabilities. $J$ Child Dev Disord 2:3

Wortsman J, Matsuoka LY, Chen TC, Lu Z \& Holick MF (2000). Decreased bioavailability of vitamin D in obesity. Am J Clin Nutri 72:690-3.

Xiang F, Jiang J, Li H, Yuan J, Yang R, Wang Q $\&$ Zhang Y (2013). High prevalence of vitamin $\mathrm{D}$ insufficiency in pregnant women working indoors and residing in Guiyang, China. $J$ Endocrinol Invest 36:503-507.

Yong HY, Mohd Shariff Z, Rejali Z, Mohd Yusof B, Yasmin F \& Palaniveloo L (2018). Seremban Cohort Study (SECOST): a prospective study of determinants and pregnancy outcomes of maternal glycaemia in Malaysia. BMJ Open 8:e018321. 